\title{
Comparative Study between Early and Late Laparoscopic Cholecystectomy in the Treatment of Acute Cholecystitis
}

\author{
Gulab Dhar Yadav ${ }^{1}$, Manish Kumar ${ }^{2 *}$ \\ ${ }^{1}$ Professor, Department of General Surgery, GSVM Medical College, Kanpur, India \\ ${ }^{2}$ Junior Resident, Department of General Surgery, GSVM Medical College, Kanpur, India
}

\begin{abstract}
*Address for Correspondence: Dr. Manish Kumar, Junior Resident III, Department of Surgery, GSVM Medical College, Kanpur, India
\end{abstract}

E-mail: manishkumarmak53@gmail.com

Received: 30 Jan 2020/ Revised: 27 Mar 2020/ Accepted: 26 Apr 2020

\begin{abstract}
Background: Laparoscopic cholecystectomy (LC) has become the gold standard in the treatment of symptomatic gallbladder stone. The common opinion about the treatment of acute cholecystitis (AC) is initially conservative treatment due to preventing complications of inflammation and following delayed laparoscopic cholecystectomy after 6-8 weeks. However, with the increase of laparoscopic experience in recent years, early LC has become more common.

Methods: This study included 40 patients of AC with comparison between early (20 patients) and delayed (20 patients) LC. In AC, initial conservative treatment was given and early LC performed within 72 hours and delayed LC was done after 6-8 weeks, both groups monitored since admission, during operations, and along the postoperative (PO) period.

Results: There was a significant difference in the successful LC conversion rates out of 20 each (20 early versus 19 delayed, $p$ value $=0.000$ ), and conversion, open cholecystectomy $(\mathrm{OC})$ to delay cholecystectomy conversion rates $5 \%$ or complication was found in delayed out of 20 in adhesion was $20 \%$, wound Infection $1 \%$ and pain $15 \%$; hospital stay was more significant in delayed LC 0.007 and USG finding in compared between early and delayed, was more common in delayed LC.

Conclusion: Intraoperative and PO complications being associated more with delayed LC as compared to early LC, so early LC should be preferred for treatment of AC.
\end{abstract}

Key-words: Acute cholecystitis, Early laparoscopic cholecystectomy, Delayed laparoscopic cholecystectomy, Open cholecystectomy

\section{INTRODUCTION}

The prevalence of cholesterol gallstones is increased in obese people. The risk is particularly high in those with a higher weight record. Weight reduction further builds the danger of gallstones. Around 33\% of the stones are symptomatic. The expanded predominance of stones is generally because of super-saturation of bile with cholesterol, due to increased synthesis by the liver and emission into bile. Saturation is additionally increased during weight reduction ${ }^{[1,2]}$. LC is a method of choice in the management of calculus gallbladder disease in the general population.

\section{How to cite this article}

Yadav GD, Kumar M. Comparative Study between Early and Late Laparoscopic Cholecystectomy in the Treatment of Acute Cholecystitis. SSR Inst. Int. J. Life Sci., 2020; 6(3): 2588-2593.

Access this article online
https://ijils.com/

Laparoscopic cholecystectomy has become the gold standard in the treatment of symptomatic gallstone disease. The significant points of interest of LC incorporate less PO pain, less time required for hospitalization and recovery and better cosmetic results. The general view in the treatment of $A C$ is to firstly administer conservative therapy to prevent possible complications associated with inflammation and afterwards following 6 to about 8 weeks, to perform LC. Although over $70 \%$ of such patients respond to clinical treatment within the initial 24 to 48 hours ${ }^{[3,4]}$.

The benefits of this minimally invasive technique over open surgery are less PO pain, earlier mobilization; less pulmonary function impairment, decreased operative stress, and a shorter hospital stay ${ }^{[5]}$. Be that as it may, the ideal timing of cholecystectomy in patients with $\mathrm{AC}$ stays disputable. The refreshed Tokyo Guidelines propose that an early laparoscopic cholecystectomy (ELC) is compulsory for patients with mild cholecystitis, 
whereas delayed laparoscopic cholecystectomy (DLC) can be performed in patients with moderate or severe cholecystitis ${ }^{[6]}$. The customary treatment (introductory) of acute calculus cholecystitis incorporates bowel rest, intravenous hydration, and normalization of electrolyte abnormalities, analgesia, and intravenous antibiotics ${ }^{[7-10] \text {. }}$ As this strategy, requested a tremendous involvement with $L C$, the number of specialists performing early $L C$ for $A C$ in India is little inferable from the late presentation of methodology in our nation. Till now, the specific planning and potential advantages of early laparoscopic removal of gall bladder have not been settled and keep on being questionable ${ }^{[11]}$. Anyway, with the increase of laparoscopic involvement with ongoing years, early LC has gotten increasingly more common.

\section{MATERIALS AND METHODS}

The study was based on case-control and conducted in the Department of General Surgery, Associate LLRM Hospitals, GSVM Medical College, Kanpur, India from January 2018 to October 2019 on patients, who were admitted from casualty and outpatients department with a diagnosis of $\mathrm{AC}$.

\section{Inclusion criteria}

$>$ Age group $>15-70$ years

$>$ Symptomatic gallstone disease (SGBS)

- Biliary colic pain

- Acute cholecystitis

\section{Exclusion criteria}

$>$ Age below 15 or above 70 years

$>$ Not willing to participate

$>$ Severe concomitant disease

$>$ Suspected Common Bile Duct stone

$>$ Asymptomatic gall stone disease

$>$ Acalculous cholecystitis

Selection of Early and Late laparoscopic cholecystectomy- Evaluation of these patients would be based on patient's characteristics, comprehensive study, hematological and radiological parameter, these patients would be taken for LC. Those patients, who were not fit or not willing for LC would be undergone OC.

The patients, who presented with $A C$ was divided into two groups on alternate basis patients of one group go for early surgery within 72 hours onset of symptoms and the other group was managed conservatively and was undergone LC after 6 weeks. The comparison was done between operative parameters of both the groups.

\section{Operative parameters}

(a) Assess to peritoneal cavity: Access will be also designated as easy or difficult.

(b) Gall bladder dimension: GB will be either designated as contracted, normal or distended (as in mucocele or empyema).

(c) Calot's triangle anatomy: Calot's triangle anatomy will be designated normal, variable or obscure.

(d) Calots triangle adhesions: Adhesions would be mentioned either present or absent.

(e) Calot's triangle dissection: will be designated as easy or difficult.

(f) Dissection of gall bladder from bed: Designated as easy or difficult.

(g) Spillage of bile and stones: Designated as yes or no.

(h) Duration of Surgery: Duration of surgery will be defined as the time taken from the first incision to the closure of the last port.

(i) Conversion to open: Conversion to open will be designated as yes or no and cause of conversion was mentioned.

Statistical Analysis- The results are presented in mean $\pm S D$, percentage and chi square test. Percentage of test was used to compare the categorical variables between present or absent complication. The $p$ value $<0.05$ was considered significant. All the analysis was carried out by using SPSS 21.0 version (Chicago, Inc., USA).

\section{RESULTS}

Demographic findings- As depicted in Table 1, the study groups, which underwent early or delayed laparoscopic cholecystectomy, showed no difference in age and sex distribution. Initial clinical findings and medical history were also similar between groups, except for the fever, which was significantly higher in the delayed to early LC group $(54.77 \pm 10.57$ versus $43.2 \pm 2.76 ; p=0.0001)$ respectively. 
Table 1: Demographic data of patients in the early and delayed LC groups

\begin{tabular}{cccc}
\hline Variables & $\begin{array}{c}\text { Early LC } \\
(\mathbf{n}=\mathbf{2 0})\end{array}$ & $\begin{array}{c}\text { Delayed LC } \\
(\mathbf{n}=\mathbf{2 0})\end{array}$ & p-Value \\
\hline Age & $30.5 \pm 7.52$ & $40.12 \pm 13.04$ & 0.006 \\
Sex (\%) & & & \\
Male & $0(0)$ & $2(10)$ & $>0.05$ \\
Female & $20(100)$ & $18(90)$ & 0.1705 \\
Hospital & $2.4 \pm 0.50$ & $2.7 \pm 0.82$ & 0.6753 \\
stay & & $1.8 \pm 0.383$ & \\
$\quad \begin{array}{c}\text { Pain } \\
\text { duration } \\
\text { (h) }\end{array}$ & $1.85 \pm 0.366$ & & 0.0001 \\
$\begin{array}{c}\text { Operation } \\
\text { time }\end{array}$ & $43.2 \pm 2.76$ & $54.77 \pm 10.57$ & \\
\hline
\end{tabular}

The complication rate, conversion to early laparoscopic cholecystectomy and duration of surgery showed no significant differences between early and late laparoscopic cholecystectomy except for jaundice no complications for the early and delayed LC group (Table 2).

Table 2: Complications early and delayed LC groups

\begin{tabular}{ccc}
\hline Complains & Early (n=20) & $\begin{array}{c}\text { Delayed } \\
(\mathbf{n}=\mathbf{2 0})\end{array}$ \\
\hline Present & $20(100 \%)$ & $3(15 \%)$ \\
Absent & $0(0 \%)$ & $17(85 \%)$ \\
Right Hypochondrial Pain & \\
Present & Fever & $1(5 \%)$ \\
Absent & $3(15 \%)$ & $19(95 \%)$ \\
& $17(85 \%)$ & \\
Present & Vomiting & $0(0 \%)$ \\
Absent & $12(60 \%)$ & $20(100 \%)$ \\
& $8(40 \%)$ & $2(10 \%)$ \\
Present & Nausea & $18(90 \%)$ \\
Absent & $8(40 \%)$ & \\
& $12(60 \%)$ & $0(0 \%)$ \\
Present & Jaundice & $20(100 \%)$ \\
Absent & $0(0 \%)$ &
\end{tabular}

In Table 3, total each group 20 patients undergone USG finding of the whole abdomen, in early and LC size distended (100\%), gall bladder wall thickness (100\%), multiple stones (100\%), CBD normal (100\%), IHBR not dilated (100\%); in delayed LC bladder size distended (40\%) and normal (60\%), gall bladder wall thickness $(85 \%)$ and normal (15\%), multiple stones (80\%) and solitary stone $(20 \%)$, CBD normal $(100 \%)$, IHBR normal (100\%), respectively.

Table 3: USG findings in early and delayed laparoscopic Cholecystectomy

\begin{tabular}{ccc}
\hline USG Finding & Early $(\mathbf{n}=\mathbf{2 0})$ & Delayed $(\mathbf{n = 2 0})$ \\
\hline \multicolumn{3}{c}{ Gall Bladder Size } \\
Distended & $20(100 \%)$ & $8(40 \%)$ \\
Normal & $0(0 \%)$ & $12(60 \%)$
\end{tabular}

Gall bladder wall thickness

\begin{tabular}{ccc} 
Normal & $0(0 \%)$ & $3(15 \%)$ \\
Thickened & $20(100 \%)$ & $17(85 \%)$ \\
& Gall Bladder Stone & \\
Multiple Stone & $20(100 \%)$ & $16(80 \%)$ \\
Solitary Stone & $0(0 \%)$ & $4(20 \%)$ \\
& CBD & \\
Normal & $20(100 \%)$ & $20(100 \%)$ \\
Dilated & $0(0 \%)$ & $0(0 \%)$ \\
& IHBR & \\
Dilated & $0(0 \%)$ & $0(0 \%)$ \\
Normal & $20(100 \%)$ & $20(100 \%)$ \\
\hline
\end{tabular}

IHBR= Intrahepatic Biliary Radicals, CBD= Common Bile Duct

Table 4 shows the pearson correlation between hospital stay in early LC to delayed LC was positive significant $(p=$ 0.007 ) and delayed LC to early LC was not significant correlation ( $p=0.295)$, respectively.

Table 5 shows the conversion rate in early was $0 \%$ and in delayed cases, conversion to Open Cholecystectomy $(5 \%)$; It was statically significant ( $p$ value $=0.000$ ) respectively. 
Table 4: Comparison of hospital stays in early and delayed laparoscopic Cholecystectomy

\section{Early LC Delayed LC}

\begin{tabular}{|c|c|c|c|}
\hline \multirow[t]{5}{*}{$\begin{array}{c}\text { Early } \\
\text { cholecystectomy }\end{array}$} & $\begin{array}{l}\text { Pearson } \\
\text { Correlation }\end{array}$ & 1 & -.246 \\
\hline & $\begin{array}{l}\text { Sig. (2- } \\
\text { tailed) }\end{array}$ & $0.007^{*}$ & .295 \\
\hline & $\begin{array}{c}\text { Sum of } \\
\text { Squares and } \\
\text { Cross- } \\
\text { products }\end{array}$ & 4.800 & -2.000 \\
\hline & Covariance & .253 & -.105 \\
\hline & $\mathrm{N}$ & 20 & 20 \\
\hline \multirow[t]{5}{*}{$\begin{array}{c}\text { Delayed } \\
\text { cholecystectomy }\end{array}$} & $\begin{array}{l}\text { Pearson } \\
\text { Correlation }\end{array}$ & -.246 & 1 \\
\hline & $\begin{array}{l}\text { Sig. (2- } \\
\text { tailed) }\end{array}$ & .295 & $0.007 *$ \\
\hline & $\begin{array}{c}\text { Sum of } \\
\text { Squares and } \\
\text { Cross- } \\
\text { products }\end{array}$ & -2.000 & 13.750 \\
\hline & Covariance & -.105 & .724 \\
\hline & $\mathrm{N}$ & 20 & 20 \\
\hline
\end{tabular}

LC- Laparoscopic cholecystectomy

Table 5: Comparison of conversion rate in early and delayed LC

\begin{tabular}{cccc}
\hline Procedure & $\begin{array}{c}\text { Early } \\
(\mathbf{n}=\mathbf{2 0})\end{array}$ & $\begin{array}{c}\text { Delayed } \\
(\mathbf{n}=\mathbf{2 0})\end{array}$ & $\mathbf{p}=$ value \\
\hline $\begin{array}{c}\text { Successful } \\
\text { LC }\end{array}$ & 20 & 19 & \\
$\begin{array}{c}\text { Conversion } \\
\text { to OC }\end{array}$ & 0 & 1 & $0.000^{*}$ \\
$\begin{array}{c}\text { Conversion } \\
\text { rate }\end{array}$ & $0 \%$ & $5 \%$ & \\
\hline
\end{tabular}

$\overline{\mathrm{OC}}=$ Open cholecystectomy, LC= Laparoscopic cholecystectomy

Table 6 shows the correlation between intra operative was CBD injury in early and delayed statically significance ( $p$-value $=0.00$ ) with no complication. GIT injury in early and delayed statically significance ( $p$-value $=0.00$ ) with no complication. Adhesion in delayed LC was found (20\%). In post operative delayed, LC complication was wound infection (5\%) and pain (15\%) found.
Table 6: Comparison of complication in early and delayed LC in intra and post operative cases

\begin{tabular}{|c|c|c|}
\hline $\begin{array}{c}\text { Complication } \\
\text { (Intra Operative) }\end{array}$ & $\begin{array}{c}\text { Early } \\
\text { Laparoscopic } \\
(n=20)\end{array}$ & $\begin{array}{c}\text { Delayed } \\
\text { Laparoscopic } \\
(n=20)\end{array}$ \\
\hline CBD Injury & $0(0 \%)$ & $0(0 \%)$ \\
\hline GIT Injury & $0(0 \%)$ & $0(0 \%)$ \\
\hline & Adhesion & \\
\hline Found & $0(0 \%)$ & $4(20 \%)$ \\
\hline Not Found & $0(0 \%)$ & $16(80 \%)$ \\
\hline \multicolumn{3}{|c|}{ Complication (Post Operative) } \\
\hline Biliary Leakage & $0(0 \%)$ & $0(0 \%)$ \\
\hline Wound Infection & $0(0 \%)$ & $1(5 \%)$ \\
\hline \multicolumn{3}{|c|}{ Pain } \\
\hline Yes & $0(0 \%)$ & $3(15 \%)$ \\
\hline No & $0(0 \%)$ & $17(85 \%)$ \\
\hline
\end{tabular}

Intra-abdominal gastrointestinal Injury (GIT Injury), Common Bile Duct (CBD)

\section{DISCUSSION}

The occurrence of gall stone disease is on a rise globally due to vast dietary changes, way of life changes related to high junk diet utilization and increment inactive way of life alteration. The predominance of cholelithiasis (acute and chronic) is variable and has been accounted for like 2-29\% in India with differences in interstate and interregional. The commonness was generally normal among North Indians than South Indians especially among the individuals of the seaside locale. This is mostly credited to westernization and facilitates of accessibility of examination under USG or looks for clinical consideration because of episodic pain in the abdomen. Cholelithiasis is a very common surgical problem.

The aggregate of 40 cases were included in the present study and informed written consent was acquired from all the cases. Beksac et al. ${ }^{[12]}$ described in their study, age group from 15 years to 70 years of $A C$ were most common during the early LC of the most widely recognized age group $26-35$ years (40\%) and delayed LC of the most well-known age group 36-45 years (55\%). The mean age of the study group was early $(30.5 \pm 7.52)$, delayed $(40.12 \pm 13.04)$ and statically importance $p$-value 0.006 . the comparable study was observed by Pimpale et 
al. ${ }^{[13]}$, total of 92 patients were enlisted of which 62 (68.89\%) were female, with mean period of $45.03 \pm 13.59$. LC was done in $71(77.17 \%)$ patients with a conversion rate of $6.57 \%$. Total 19 (20.65\%) were OC with or without CBD exploration and 2 experienced LC. Gender distribution in early male (0\%) and female (100\%) and Delayed Laparoscopic male (10\%) and female $(90 \%)$ it isn't significant (0.993).

Previous study i.e. Zhong et al. ${ }^{[14]}$ was similar to our study, the overall morbidity and complications are less in ELC contrasted with DLC. Mean number of hospital stay was less in ELC (4.90\%), while DLC (6.30\%). The mean number of long periods of anti-microbial inclusion was less in ELC (3.9 days) in compared to DLC (5.30 days). Mean operative time was less in ELC (60 minutes) and DLC (82 minutes). Overall the complications, morbidity, mortality, ICU admissions, and readmissions are less in early LC (Madhu and Kumar ${ }^{[15]}$ ) at the similar study preferred to our approach for patients managed by surgeon with adequate experience in LC.

In past study, Verma et al. ${ }^{[16]}$ was found no significant difference in the conversion rates (3 early versus 2 delayed), PO analgesia requirements, postoperative pain scores, or span of postoperative stay (1.67 days early versus 1.47 days delayed). Our study concluded that early LC for AC is safe and feasible, offering the extra advantage of a shorter hospital stays. It should be offered to patients with $A C$, provided the surgery is performed within $72 \mathrm{~h}$ from the beginning of side effects.

Ozkardes et al. ${ }^{[17]}$ past outcome was compared about the clinical result and cost of early versus delayed $L C$ for AC. Sixty patients with AC were randomized into early (within 72 hours of admission) or delayed (following 6-8 weeks of conservative treatment) LC groups. Intraoperative and PO complications were recorded in 8 patients in the delayed LC groups, whereas no complications happened in the early LC groups $(P=0.002)$. Our study was finding that of intraoperative and $\mathrm{PO}$ complexities being related more with delayed $\mathrm{LC}$ compared with early intervention, early LC should be favored for treatment of $A C$ as a result of its advantages of shorter hospital stay and lower cost.

\section{CONCLUSIONS}

The level of difficulty in technique, peri-operative and post-operative complication and hospital stay were higher in delayed laparoscopic cholecystectomy. If surgeons with adequate experience and laparoscopic cholecystectomy for acute cholecystitis performed within 72 hours of admission then above complications were reduced.

Finally, the outcome of this study was intra-operative and PO complications being associated more with delayed LC as compared to early LC, so early LC should be preferred for treatment of AC.

\section{CONTRIBUTION OF AUTHORS}

Research concept- Prof. GD Yadav, Dr. Manish Kumar

Research design- Dr. Manish Kumar

Supervision- Prof. GD Yadav

Materials- Dr. Manish Kumar

Data collection- Dr. Manish Kumar

Data analysis and Interpretation- Prof. GD Yadav, Dr.

Manish Kumar

Literature search- Dr. Manish Kumar

Writing article- Dr. Manish Kumar

Critical review- Prof. GD Yadav

Article editing- Dr. Manish Kumar

Final approval- Prof. GD Yadav

\section{REFERENCES}

[1] Festi D, Colecchia A, Orsini M, et al. Gallbladder motility and gallstone formation in obese patients following very low calorie diets. Use it (fat) to lose it (well). Int J Obes Relat Metab Disord., 1998; 22: 592600.

[2] Erlinger S. Gallstones in obesity and weight loss. Eur J Gastroenterol Hepatol., 2000; 12: 1347-52.

[3] Overby DW, Apelgren KN, Richardson W, et al. SAGES guidelines for the clinical application of laparoscopic biliary tract surgery. Surg Endosc., 2010; 24: 236886.

[4] Ansaloni L, Pisano M, Coccolini F, et al. WSES guidelines on acute calculous cholecystitis. World J Emerg Surg., 2016; 11: 25.

[5] Kuhry E, Jeekel J, Bonjer HJ. Effect of laparoscopy on the immune system. Semin Laparosc Surg., 2004; 11: 37-44.

[6] Gomi H, Solomkin JS, Takada T, Strasberg SM, Pitt $H A$, et al. TG13 antimicrobial therapy for acute cholangitis and cholecystitis. J Hepatobiliary Pancreat Sci., 2013; 20: 60-70.

[7] Cuschieri A, Dubois F, Mouiel J, et al. The European experience with laparoscopic cholecystectomy, Am J Surg., 1991; 161(3): 385-87. 
[8] Sandzen B, Haapamaki MM, Nilsson E, Stenlund HC, Oman M. Surgery for acute gallbladder disease in Sweden 1989-2006- a register study. Scand J Gastroenterol., 2013; 48(4): 480-86.

[9] Falor AE, de Virgilio C, Stabile BE, Kaji AH, Caton A, et al. Early laparoscopic cholecystectomy for mild gallstone pancreatitis: time for a paradigm shift. Arc Surg., 2012; 147(11): 1031-35.

[10]Panagiotopoulou IG, Carter N, Lewis MC, Rao S. Early laparoscopic cholecystectomy in a district general hospital: is it safe and feasible? Int J Evid Based Health, 2012; 10(2): 112-16.

[11]Sankarankutty A, da Luz LT, De Campos T, Rizoli S, Fraga GP, et al. Uncomplicated acute cholecystitis: early or delayed laparoscopic cholecystectomy? Rev Col Bras Cir., 2012; 39(5): 436-40.

[12]Beksac K, Turhan N, Karaagaoglu E, Abbasoglu O. Risk Factors for Conversion of Laparoscopic Cholecystectomy to Open Surgery: A New Predictive Statistical Model.J Laparoendosc Adv Surg Tech., 2016; 26 (9): 693-96.
[13]Pimpale R, Katakwar P, Akhtar M. Cholelithiasis: causative factors, clinical manifestations and management. Int Surg J., 2019; 6: 2133-38.

[14]Zhong FP, Wang K, Tan XQ, Nie J, Huang WF, et al. The optimal timing of laparoscopic cholecystectomy in patients with mild gallstone pancreatitis: A metaanalysis. Medicine (Baltimore), 2019; 98(40): e17429.

[15]Madhu CP, Kumar SRM. Compare the effectiveness of early versus delayed laparoscopic cholecystectomy in acute calculus cholecystitis. Int Surg J., 2018; 5: 695-700.

[16]Verma S, Agarwal PN, Bali RS, Singh R, et al. Early versus Delayed Laparoscopic Cholecystectomy for Acute Cholecystitis: A Prospective Randomized Trial. ISRN Minimally Invasive Surg., 2013: 1-3.

[17] Ozkardes AB, Tokaç M, Dumlu EG, et al. Early versus delayed laparoscopic cholecystectomy for acute cholecystitis: a prospective, randomized study. Int Surg., 2014; 99(1): 56-61. 